\title{
A study of clinico-demographic profile of patients with dissociative disorder
}

\section{SK Shah}

Lecturer, Department of Psychiatry, College of Medical Sciences Teaching Hospital, Bharatpur, Nepal

\section{ABSTRACT}

\section{Objectives}

To study the clinical and socio demographic profile of patients with dissociative disorder and their comorbid mental illness.

\section{Materials and methods}

Fifty-one patients of dissociative disorder presenting to emergency and outpatient department of Psychiatry at College of Medical Sciences Teaching Hospital during the period from Jan to March 2012 were included. International statistical classification of diseases and related health problems tenth edition, diagnostic criteria for research (ICD-10, DCR) was used.

\section{Results}

Out of 51 patients, the majority 24 (47.1\%), were in the age group 15-29. However the age of presentation ranged from 9-45 years. The females were more, $44(86.3 \%)$ as compared to males 7 (13.7\%). The majority of patients had low level of education with none of the patients having education above intermediate level. The majority of patients, $27(52.9 \%)$ belonged to lower middle class. $49 \%$ of the patients presented with dissociative convulsions, $15.7 \%$ with dissociative motor disorders, $15.7 \%$ with dissociative stupor, $11.8 \%$ with dissociative anesthesia and sensory loss and $7.8 \%$ with trance and possession disorder. Depressive illness was found co-morbid with dissociative disorder in 33.3\%, borderline personality disorder in $9.8 \%$ and histrionic personality disorder in $7.8 \%$. There was history of immediate stressful events that supposedly precipitated the event in $76.5 \%$.

\section{Conclusion}

Dissociative disorder mainly affects young female of lower socio-economic and educational status with history of immediate stressful life events precipitating the illness.

\section{Key words: Co-morbid mental illness, dissociative disorder, stressful life events.}

Correspondence: Dr. SK Shah

E-mail:sunil_shah38@yahoo.com 
SK Shah, A study of clinico-demographic profile of patients with dissociative disorder.......

\section{Introduction}

Dissociation is defined as a disruption in the usually integrated functions of consciousness, memory, identity, or perception of the environment. ${ }^{1}$ In dissociative disorders, there is disturbance in the normal integration between memory and awareness of identity, immediate sensations and control of bodily movements. No evidence of a physical disorder that can explain the symptoms that characterizes the disorder and convincing associations in time between the symptoms of the disorder and stressful events, problems or need are required. ${ }^{2}$

Incidence and prevalence of dissociative disorder vary across various countries and communities. Compared to developed western countries, it is more prevalent in developing countries. ${ }^{3,4}$ Dissociative disorders have a lifetime prevalence of about $10 \% .{ }^{5}$ In a study from Zurich, Switzerland, among severely impaired psychiatric outpatients, prevalence of all dissociative disorders was $25 \%{ }^{6}$

Most studies reports that dissociative disorders occur mostly in people younger than 30 yrs with mean age group 22 to 25 years and female sex. ${ }^{7,8}$ The seemingly dominance of dissociative disorders in women may also depend on the socio-cultural context, because men with dissociative disorders usually do not enter the general health system, but rather the legal system, i.e. they can be found in jail or forensic institutions. ${ }^{9}$

This study was conducted to observe the sociodemographic profile of patients and the clinical presentation of dissociative patients.

\section{Materials and Methods}

This study is hospital based cross-sectional study, conducted in patients presenting with dissociative disorder in emergency and psychiatry OPD at CMSTH during the period from January to march 2012, after clearance from the institutional ethical committee.

Patients not willing to take part and those with comorbid physical illnesses, like diabetes mellitus, hypertension, stroke, neuropathies, movement disorders were excluded. Socio-demographic profile was documented with a semi-structured proforma and ICD-10 DCR was followed for the diagnosis. Data collected were analyzed using SPSS 20.

\section{Results}

A total of 51 patients with dissociative disorder were included in the study. The table 1 shows, the majority of patients, 24 (47.1\%) were in the age group 15-29. The patients below 29 years were 34 (66.7\%). There was statistical difference in the various age groups $(\mathrm{p}=0.001)$.

The table 2 shows the mean age of presentation of patients with dissociative disorders was 25.71. The minimum age of presentation was 9 years and the maximum was 45 yrs. $(\mathrm{p}=0.510)$.

The table 3 shows that out of the total 51, 44 (86.3\%) were females and 7 (13.7\%) were females. The number of female patients was statistically significantly higher $(\mathrm{p}=0.000)$.

The table 4 shows all of the patients were educated upto intermediate level or below. Patients educated upto high school or below were $86.3 \%$ but its distribution in the various educational levels was not different statistically $(\mathrm{p}=0.433)$. 
Table 2: Age of presentation

The table 5 shows that majority of the patients $52.9 \%$ belonged to the lower middle class. The distribution of patients in various socioeconomic status groups was statistically different $(\mathrm{p}=0.000)$.

The table 6 shows that $49 \%$ of the patients presented with dissociative convulsions, $15.7 \%$ with dissociative motor disorders, $15.7 \%$ with dissociative stupor, $11.8 \%$ with dissociative anesthesia and sensory loss and $7.8 \%$ with trance and possession disorder. Subcategories of different types of dissociative disorder did not occur with equal probabilities $(\mathrm{p}=0.000)$.

The table 7 shows that depressive illness was found comorbid with dissociative disorder in 33.3\%, borderline personality disorder in $9.8 \%$ and histrionic personality disorder was found in $7.8 \%$ of the cases. There was statistical difference in presence of comorbid mental illnesses $(\mathrm{p}=0.000)$.

The table 8 shows that there was history of immediate stressful events that supposedly precipitated the event obviously in $76.5 \%$ of the cases. There was statistically significant difference in the no of patients whose illness was precipitated by immediate stressful events $(p=0.000)$.

Table 1: Age group distribution of cases

\begin{tabular}{|c|c|c|c|}
\hline $\begin{array}{l}\text { Age group } \\
\text { in } \\
\text { years }\end{array}$ & Frequency & Percent & $\begin{array}{c}\text { Level of } \\
\text { significance } \\
\text { p value }\end{array}$ \\
\hline$<15$ & 10 & 19.6 & 0.001 \\
\hline $15-29$ & 24 & 47.1 & \\
\hline $30-44$ & 13 & 25.5 & \\
\hline$>44$ & 4 & 7.8 & \\
\hline Total (N) & 51 & 100.0 & \\
\hline
\end{tabular}

\begin{tabular}{lcc}
\hline & $\begin{array}{c}\text { Age } \\
\text { prgentaiton }\end{array}$ & $\begin{array}{c}\text { Level of significance } \\
\text { p value }\end{array}$ \\
\hline Mean & 25.71 & \\
Std. Deviation & 10.832 & 0.510 \\
Minimum & 9 & \\
Maximum & 45 & \\
\hline
\end{tabular}

Table 3: Sex of the patients

\begin{tabular}{lccc}
\hline $\begin{array}{l}\text { Sex } \\
\text { in years } \\
\text { significance }\end{array}$ & Frequency & Percent & Level of \\
value & & & p \\
\hline Male & 7 & 13.7 & 0.000 \\
Female & 44 & 86.3 & \\
Total & $\mathbf{5 1}$ & $\mathbf{1 0 0 . 0}$ & \\
\hline
\end{tabular}

Table 4: Educational status

\begin{tabular}{lccc}
\hline $\begin{array}{l}\text { Educational } \\
\text { status }\end{array}$ & Frequency & Percent & $\begin{array}{c}\text { Level of } \\
\text { significance } \\
\text { p value }\end{array}$ \\
\hline Intermediate & 7 & 13.7 & 0.433 \\
High school & 14 & 27.5 & \\
Middle school & 11 & 21.6 & \\
Primary school & 12 & 23.5 & \\
Illiterate & 7 & 13.7 & \\
Total & $\mathbf{5 1}$ & $\mathbf{1 0 0 . 0}$ & \\
\hline & & &
\end{tabular}

Table 5- Socioeconomic status

\begin{tabular}{lccc}
\hline SES & Percent & & $\begin{array}{c}\text { Level of } \\
\text { significance } \\
\text { p value }\end{array}$ \\
\hline Upper middle & 7 & 13.7 & 0.000 \\
Lower middle & 27 & 52.9 & \\
Upper lower & 15 & 29.4 & \\
Lower & 2 & 3.9 &
\end{tabular}


SK Shah, A study of clinico-demographic profile of patients with dissociative disorder.......

\begin{tabular}{|c|c|c|c|}
\hline \multirow{2}{*}{\multicolumn{4}{|c|}{$\begin{array}{lcc}\text { Total } & 51 & 100.0 \\
\text { Table 6: Subtype of the disorder }\end{array}$}} \\
\hline & & & \\
\hline \multicolumn{2}{|c|}{ Subtypes } & \multicolumn{2}{|c|}{ Level of of } \\
\hline \multicolumn{2}{|c|}{ dissociativeFrequency } & \multicolumn{2}{|c|}{$\%$ significance } \\
\hline \multicolumn{2}{|l|}{ disorder } & \multicolumn{2}{|c|}{ p value } \\
\hline Dissociativestupor & 8 & 15.7 & 0.000 \\
\hline \multicolumn{4}{|l|}{ Trance and possession } \\
\hline disorder & 4 & \multicolumn{2}{|l|}{7.8} \\
\hline Dissociative motor disorc & s 8 & \multicolumn{2}{|l|}{15.7} \\
\hline Dissociative convulsions & 25 & \multicolumn{2}{|l|}{49.0} \\
\hline \multicolumn{4}{|l|}{ Dissociative anesthesia } \\
\hline and sensory loss & 6 & \multicolumn{2}{|l|}{11.8} \\
\hline Total & 51 & \multicolumn{2}{|l|}{100.0} \\
\hline
\end{tabular}

\begin{tabular}{|c|c|c|c|}
\hline \multirow{2}{*}{\multicolumn{2}{|c|}{$\begin{array}{ll}\text { Comorbid } & \\
\text { mental } & \text { Frequency } \\
\text { illnesses } & \end{array}$}} & \multicolumn{2}{|c|}{$\begin{array}{c}\text { Level of } \\
\text { significance }\end{array}$} \\
\hline & & \multicolumn{2}{|c|}{$p$ value } \\
\hline Depressive episode & 17 & 33.3 & 0.000 \\
\hline \multicolumn{4}{|l|}{ Borderline personality } \\
\hline disorder & 5 & 9.8 & \\
\hline \multicolumn{4}{|l|}{ Histrionic personality } \\
\hline disorder & 4 & 7.8 & \\
\hline Absent & 25 & 49.0 & \\
\hline Total & 51 & 100.0 & \\
\hline
\end{tabular}

Table 8: Immediate stressful events precipitating the illness

\begin{tabular}{lccc}
$\begin{array}{l}\text { Precipitating } \\
\text { immediate }\end{array}$ & Frequency & $\%$ & $\begin{array}{c}\text { Level of } \\
\text { significance } \\
\text { events }\end{array}$ \\
\hline No & 12 & 23.5 & 0.000 \\
Yes & 39 & 76.5 & \\
Total & $\mathbf{5 1}$ & $\mathbf{1 0 0 . 0}$ & \\
\hline
\end{tabular}

\section{Discussion}

This study included 51 patients presenting to our hospital with dissociative disorder. The patients' age ranged from 9-45 years, with mean age of patients 25.71 yrs. The majority of patients 24 (47.1\%) were within 15-29 yrs. A total of 34 (66.7\%) were below 29 years. In a similar study conducted in eastern part of Nepal, mean age of patients was 21.23 years with majority of the patients (84.5\%) being less than 30 years of age ${ }^{10}$. Chand SP et al reported that the mean age of the patients with dissociative disorders was 22.4 years and $80.0 \%$ of the patients were less than 30 years of age $e^{8}$. In another similar study conducted in Saudi Arabia, $80 \%$ of the patients with dissociative disorders were less than 30 years of age $\mathrm{e}^{7}$. In our study, $86.3 \%$ of the patients were female and $86.3 \%$ had education upto high school level or below. The majority of the patients belonged to the lower middle class $52.9 \%$. Forty-nine percent (49\%) of the patients presented with dissociative convulsions, $15.7 \%$ with dissociative motor disorders, $15.7 \%$ with dissociative stupor, $11.8 \%$ with dissociative anesthesia and sensory loss and 7.8\% with trance and possession disorder. In a similar study conducted at BPKIHS, out of 39 patients 15 were of Dissociative convulsion, 10 of Dissociative motor disorder and 12 of Dissociative stupor ${ }^{10}$. In a prevalence study conducted in New York, twenty-four (29\%) of the 82 patients who were interviewed met the criteria for a DSM-IV dissociative disorder diagnosis, with the diagnoses distributed as follows: dissociative amnesia, $\mathrm{N}=8(10 \%)$; dissociative disorder not otherwise specified, $\mathrm{N}=7$ (9\%); dissociative identity disorder, $\mathrm{N}=5$ (6\%); and depersonalization disorder, $\mathrm{N}=4$ (5\%). None of the patients had a diagnosis of dissociative fugue. Only 
Journal of College of Medical Sciences-Nepal, 2012, Vol-8, No-3

four (5\%) of the 82 patients had a dissociative diagnosis recorded in their clinical charts ${ }^{11}$. The subtypes of dissociative disorders observed in our study were different than a study done in New York. However, there was similarity between the subtypes in our study and a study done in BPKIHS. The difference in subtypes could be due to difference in socioeconomic status, culture, lifestyle and level of education.

Depressive illness was found comorbid with dissociative disorder in $33.3 \%$, borderline personality disorder in $9.8 \%$ and histrionic personality disorder in $7.8 \%$ of the cases. There was statistical difference in presence of comorbid mental illnesses $(\mathrm{p}=0.000)$. Dissociative disorders are frequently associated with other neuropsychiatric co-morbidity ${ }^{12}$. In a outpatient study, $12 \%$ of Turkish outpatients could qualify for a diagnosis of a dissociative disorder, including $4 \%$ with dissociative identity disorder and $8 \%$ with dissociative disorder not otherwise specified. Only $1 \%$ of those patients had been given a dissociative disorder diagnosis before entering the study ${ }^{13}$. Studies especially from the developed countries have reported rather higher rates of co-morbid personality disorder. Astudy from Sweden reported that about half of the patients with dissociative disorder had personality disorder, while another study from Turkey reported that borderline personality disorder to be present in two thirds of the cases with dissociative disorder ${ }^{14}$. In a study of psychodynamics and psychiatric diagnosis of pseudo seizure subjects, personality disorder was present in $62.0 \%$ of the cases with dissociative disorder ${ }^{15}$. Depressive illness was found comorbid with dissociative disorder in 33.3\%, borderline personality disorder in 9.8\% and histrionic personality disorder was found in $7.8 \%$ of the cases. In a similar study in Istanbul, the prevalence of borderline personality disorder was 8.5\%. A significant majority (72.5\%; 58/ 80) of the borderline personality disorder group had a dissociative disorder ${ }^{16}$.

There was history of immediate stressful events that precipitated the event in $76.5 \%$ of the patients in our study. Studies have also documented that dissociative patients report highest frequencies of childhood psychological trauma among all psychiatric disorders. Childhood sexual (57.1\%-90.2\%), emotional (57.1\%), and physical (62.9\%-82.4\%) abuse and neglect (62.9\%) are among them ${ }^{17}$.

\section{Conclusion}

Dissociative disorders can have varied presentation starting as early as below 10yrs of age, usually occurring in females with low education, low socioeconomic status, usually precipitated by some stressful life-events. Comorbid mental illness like depressive episode and personality disorders need to be taken care at the same time.

\section{Reference}

1. American Psychiatric Association, Diagnostic and Statistical Manual of Mental Disorders, American Psychiatric Association, Washington, DC, USA, 4th edition, 1994.

2. World Health Organization: ICD-10 Classification of Mental and Behavioral Disorders: Clinical Descriptions and Diagnostic Guidelines. World Health Organization, Geneva. 2002; 151-61. 
SK Shah, A study of clinico-demographic profile of patients with dissociative disorder..

3. Nandi DN, Banerjee G, Nandi S, et al. Is hysteria on the wane? A community survey in West Bengal, India. Br J Psychiatry. 1992; 160; 87-91

4. Stefansson JG, Messina JS, Meyerowitz S. Hysterical neurosis, conversion type; Clinical and epidemiological considerations. Acta Psychiatr Scand. 1976; 53:119-38

5. Elmore JL. Dissociative spectrum disorders in the primary care setting. Prim Care Companion J Clin Psychiatry. 2000; 2(2): 37-41.

6. Mueller C, Moergeli H, Assoni H, et al. "Dissociative disorders among chronic and severely impaired psychiatric outpatients," Psychopathology. 2007; 40(6): 470-1.

7. Habeeb TT, Al-Zaid K, Rahim F, et al. Hysteria; A clinical and sociodemographic profile of 40 patients admitted to a teaching hospital. Ann Saudi Med. 1997; 17(1); 35-8.

8. Chand SP, Al-Hussaini AA, Martin R, et al. Dissociative disorders in the sultanate of Oman. Acta Psychiatr Scand .2000; 102; 185-7.

9. Spitzer C, Freyberger HJ. Gender differences in dissociative disorders. Bundesgesundheitsblatt Gesundheitsforschung Gesundheitsschutz. 2008; 51(1): 46-52
10. Thapa R, Shyangwa PM. Dissociative disorders: a study of clinico-demographic profile and associated stressors. Delhi Psychiatry Journal. 2010; 13 (1): 43-8.

11. Sar V, Akyuz G, Kugu N, et al. Axis I dissociative disorder comorbidity in borderline personality disorder and reports of childhood trauma. J Clin Psychiatry, 2006; 67 (10): 1583-90.

12. Merskey H. Conversion and Dissociation. New Oxford textbook of Psychiatry, Ist edition Oxford University Press. 2000;1: 1088-94.

13. Middleton W, Butler J. "Dissociative identity disorder: an Australian series," Australian and New Zealand Journal of Psychiatry.1998; 32(6), 794-804.

14. Brad F, Yvette S, Margaret K, et al. Prevalence of dissociative disorders in psychiatric outpatients. Am J Psychiatry.2006; 163:623-29.

15. Sar V, Tutkun H, Alyanak B, et al.: Frequency of dissociative disorders among psychiatric outpatients in Turkey. Compr Psychiatry. 2000; 41:216-22.

16. Binzer M, Andersen PM, Kullgren G. Clinical characteristics of patients with motor disability due to Conversion disorder. J Neurol Neurosurgery Psychiatry.1997; 63; 83-8.

17. Bowman ES, Markland ON. Psychodynamics and psychiatric diagnosis of pseudoseizure subjects. Am J Psychiatry 1996; 153(1); 57-63. 